\section{Compensation Neurosis}

Chava Creque ${ }^{1}$, Beth Kuczynski ${ }^{2}$ and Stephanie A. Kolakowsky-Hayner ${ }^{3}$

${ }^{1}$ Brain Trauma Foundation, New York City, NY, USA

${ }^{2}$ Imaging of Dementia \& Aging (IDeA)

Laboratory, Department of Neurology \& Center

for Neuroscience, University of California, Davis, CA, USA

${ }^{3}$ Stanford Concussion and Brain Performance

Center, Palo Alto, CA, USA

\section{Synonyms}

Accident neurosis; Litigation neurosis

\section{Definition}

Compensation neurosis is a condition in which symptoms are associated with a real or presumed disability (possibly exaggerated) that may bring legally awarded financial compensation. This type of neurosis is believed to be motivated in part by the desire for, and hope of, monetary or interpersonal gain. However, many factors are involved in compensation neurosis, such as the psychological factors before and after the presumed injury, the additional effects on the quality of life, the possible influences of legal or insurance processes, secondary gains of victimhood, and a feeling of being entitled to compensation. The condition may or may not resolve after financial settlement occurs. The term is often used in litigation and seems to be quite controversial in psychiatry, with some researchers disputing its existence.

\section{Cross-References}

- Fake Bad Scale

$\checkmark$ Malingering

\section{References and Readings}

Brown, J. T. (1996). Compensation neurosis rides again: A practitioner's guide to defending PTSD claims (post traumatic stress disorder). Defense Counsel Journal, 63(4), 467-482.

Hall, R. C., \& Hall, R. C. (2012). Compensation neurosis: A too quickly forgotten concept? Journal of the American Academy of Pyschiatry and the Law Online, 40(3), 390-398.

Hickling, E. J., Blanchard, E. B., \& Hickling, M. T. (2006). The psychological impact of litigation: Compensation neurosis, malingering, PTSD, secondary traumatization, and other lessons from MVAs. DePaul Law Review, 55(2), 617-633.

Rogers, R. (2008). Clinical assessment of malingering and deception (3rd ed.). New York: Guilford Press. 